\title{
Study on Challenges of Foreign Language Specialty and Innovative System in the Transformation and Development Period of Colleges
}

\author{
Fen Zhu \\ Foreign Languages School, Luoyang Institute of Science and Technology, Luoyang Henan, 471000, \\ China
}

Keywords: Transformation and development period of colleges, Foreign language specialty, Challenge, Innovative system.

\begin{abstract}
With the convening of the $3^{\text {rd }}, 4^{\text {th }}$ and $5^{\text {th }}$ Plenary Sessions of $18^{\text {th }}$ Central Committee of the CPC and the comprehensive implementation of the "13 $3^{\text {th }}$ five-year" plan, the transformation and development of Chinese colleges is in a brand-new era and colleges' reform and propulsion of all disciplines are in full swing. In such a transformation and development period, the foreign language specialty also faces many opportunities and challenges. On such a background, it is very crucial for the future development of foreign language specialty to enlarge the construction of innovative system, overcome all sorts of challenges and grasp the opportunities for development. This paper will start from the challenges of foreign language specialty in the transformation and development period of colleges to carry out an empirical research, deeply think the innovative system of foreign language specialty and give some useful suggestions on various current problems caught in colleges, in the hope of making some contributions to the development of foreign language specialty.
\end{abstract}

\section{Introduction}

With the convening of the $3^{\text {rd }}, 4^{\text {th }}$ and $5^{\text {th }}$ Plenary Sessions of $18^{\text {th }}$ Central Committee of the CPC and the comprehensive implementation of the " $13^{\text {th }}$ five-year" plan, the transformation and development of Chinese colleges is in a brand-new era and colleges' reform and propulsion of all disciplines are in full swing. In such a transformation and development period, the foreign language specialty also faces many opportunities and challenges. On such a background, it is very crucial for the future development of foreign language specialty to enlarge the construction of innovative system, overcome all sorts of challenges and grasp the opportunities for development. This paper will firstly introduce the general situation of the transformation and development era of colleges, analyze the challenges for foreign language specialty, deeply think the problems caught in foreign language specialty and try to give some thoughts and advices on the development of foreign language specialty in the transformation and development period of colleges.

\section{General situation of colleges in the transformation and development period}

The transformation and development of China' s colleges is the work which must be done when China's economic society develops in a certain period. It needs to overcome some shortcomings in the past educational system, strive to follow the pace of international education, provide a higher platform for the comprehensive development of China' s current college disciplines, and help China' s college education to comprehensively step into the trend of international development. However, in this transformation period, there will certainly be ineffective reform or inadaption in all college disciplines. To speak specifically, this is because of the problems in the system of colleges and teachers' psychological fluctuations; for the level of students, this may also exert adverse effects. At this time, it is required to point out and solve such problems, consider all sides' feelings while continuously exploring the new system, and enhance colleges' teacher faculty as well as colleges' comprehensive college-running level while guaranteeing to live through the transformation period steadily. 


\section{The country's enhanced emphasis on liberal arts}

In the current transformation and development period of colleges in China, governments, teachers and students all encounter the unprecedented opportunities and challenges. From the perspective of national policies, as a specialty of liberal arts, the foreign language specialty has its own new opportunities for development. Since 2011, the central government has made great efforts in energetically developing the public cultural undertakings and building the cultural development and prosperity. In May 2016, the General Secretary, Xi Jinping, convened the forum of philosophy and social science work in Beijing; then, he pointed out that we needed to energetically develop China' s undertakings of philosophy and social science and to show the strength of our country as a powerful cultural country. As a specialty of liberal arts, the foreign language specialty enjoys exceptional advantages because cross-culture researches cannot be separated from the foreign language, which is a tool for communication with the outside world. On this background, the emphasis on foreign language specialty has been greatly enhanced. Therefore, this is also a good opportunity for the comprehensive development of foreign language specialty. With such an opportunity, the foreign language specialty should centralize its resources for comprehensive discipline construction and scientific research. On the other hand, the foreign language specialty should also explore the innovative system and try to cultivate more excellent talents majoring foreign languages so that they can give play to their language advantages in the external communications and make more efforts and contributions to the economic and social development of China.

\section{Increased challenges for the foreign language specialty}

In the transformation and development period of China' s colleges, the foreign language specialty has enjoys its unique advantages and has good opportunities for development at all levels. However, the foreign language specialty also faces numerous challenges. In our country, the construction of foreign language specialty is always dominated by exams. Especially, the English exams constructed from primary school to high school are always the important plates for admission exams. In the transformation and development of China' s colleges, the construction of foreign language specialty should not only be oriented by exams but should focus more on the quality-oriented education for foreign language talents. As the times of examination paper is finished, it is required to simultaneously attach importance to the listening, speaking, reading and writing etc., overcome some loopholes in talent cultivation in the past and concentrate efforts on training their comprehensive quality. Meanwhile, the improvement of teachers' quality is also one of the challenges for foreign language specialty. With the new transformation and reform, can the survivors of the past teaching mode adapt to such changes? As for the teaching staff that has been teachers for a long time and are content with the current situation, they will need to deeply consider such abrupt reform in both teaching textbooks and teaching methods. Meanwhile, from the perspective of students, can students, who are used to the exam-oriented mode, adapt to this reform? It takes time to achieve a social reform and transformation; besides, we also need to make great efforts to deal with such challenges. It is required to comprehensively consider teachers, students, mode and teaching materials based on each discipline in the transformation period of colleges instead of forcibly propel the reform regardless of people' s feelings under the former mode and without rational thought in difficulties. The lessons of history told us that better development can be achieved only by respecting the objective laws. Therefore, coping with such challenges will be very helpful for the further improvement of foreign language specialty in the transformation and development period of colleges.

\section{Failure to reasonably use resources resulting in superficial reform}

With opportunities and challenges simultaneously and in the times of transformation and development of colleges, the foreign language specialty will certainly gain some supports and assistances and the resources must be increased in colleges. However, for some people, they cannot see the changes brought by such resources with their eyes and these problems reflected between 
teachers and students and in the teaching quality are negligible. The major cause for this is the improper utilization of resources. The reform only rests on slogan without showing concern for practical development of the foreign language specialty and other disciplines. Besides, this is also related to China' s colleges' history of development. To change this situation, it is required to deepen the intensity of reform and make concerted efforts from leaders to subordinates to make more contributions to the development of foreign language specialty in transformation and development period of colleges.

\section{Challenges for foreign language specialty}

Colleges face all-sided opportunities and challenges in its transformation and development period. The foreign language specialty encounters more detailed challenges, so it will be significantly helpful for the research on the innovative system of China' s foreign language specialty to systemize such challenges. Meanwhile, such challenges are also problems to be deeply thought by China' s foreign language specialty under the innovative system. When facing such problems, how to solve and enhance the comprehensive strength of foreign language specialty is the guarantee to show the validity and adaptability of the innovative system of foreign language specialty.

\section{Inadequate connotation construction}

Connotation construction, which is the construction of core competence of a discipline, is the important part to plan the development of a discipline for a long time and a guarantee concerning the long-term, innovative and comprehensive development of a discipline. The inadequate connotation construction of China' s foreign language specialty has been reflected in the transformation and development period of colleges. Before transformation, the foreign language specialty placed emphasis on all sorts of exams and neglected connotation construction all the time. Connotation construction needs the long-term planning of a discipline instead of the emphasis on employment rate and exam. Take Dalian University of Foreign Languages for example. Although it is one of few universities of foreign languages, it is a level-II university in its comprehensive competence. After the comprehensive analysis, we found it's because Dalian University of Foreign Languages lacks adequate connotation construction and disciplinary planning and fails to give full play to its own advantages. The problem of Dalian University of Foreign Languages is that it lacks top foreign language disciplines. As a result, even though it is a first-class university of foreign languages, it lacks preponderant disciplines regarding connotation evaluation and thus its disadvantage of excessively average disciplines is shown. From this point, it is required to make long-term disciplinary planning, give full play to its advantages, give full play to the university-running advantages and establish its own brand for the innovative system of foreign language specialty in the transformation and development period of colleges.

\section{Lack of top talents and unsatisfactory cultivation mechanism}

The lack of preponderant disciplines is an important problem in the transformation and development period of colleges due to the inadequate connotation construction. Besides, the foreign language specialty also shows the lack of adequate cultivation of top talents. There are only a few top talents among the talents cultivated. This does not comply with the law of cultivation of high-quality talents of the discipline. In the final analysis, this is largely related to the cultivation mechanism of foreign language specialty in colleges. Since the reform and opening-up policy, China' s need for high-quality talents has been further increased but its cultivation of college talents fails to follow the pace. Therefore, we cannot say that this is not related to the cultivation mechanism. The cultivation of top talents needs the teaching mode combining scientific research and practice, but the current mode of talent cultivation of the foreign language specialty lacks the cultivation of innovation and practicalness of talents. Take some ordinary universities of foreign languages for example. They have very limited foreign teachers on campus and this is all the more so for minority languages. Such 
problems are the major causes for inadequate top talents. Under the existing cultivation mechanism, it is required to provide talents with more development space; with such an opportunity for the transformation and development of colleges, it is required to provide talents with more platforms and more opportunities to show themselves and learn more.

\section{The teaching staff's failure to follow the international pace}

The construction of teaching staff is an important guarantee for the development of discipline, especially the development of foreign language specialty. With the arrival of the transformation and development period of colleges, many colleges in China are willing to invite some foreign teachers and it is even more so for the foreign language specialty. However, the foreign teachers' quality cannot be really guaranteed because colleges have low recruitment requirements for foreign teachers. In addition, the irregularity in the quality of domestic teachers is also one of the challenges faced by the foreign language specialty in the transformation and development period of colleges. All of these problems need to be solved by enhancing the integration intensity for qualities of teachers for the foreign language specialty. As for the assessment and evaluation of teachers, not only the academic aspect but also the teaching quality should be taken into consideration. As the teaching staff is the guarantee for the disciplinary development of foreign language specialty and the tutor for students' comprehensive quality, the construction and development of the innovative system of foreign language specialty can be promoted effectively by guaranteeing high-quality teaching staff.

\section{Colleges' insufficient emphasis and unreasonable resource allocation}

The unreasonable college resource allocation is not a short-term issue. In many colleges, the leaders prefer to provide more resources for the specialties of science and engineering so their input intensity for the specialties of liberal arts is insufficient; this is especially manifested in foreign language specialty. As for all conditions needed by talent cultivation and discipline construction of foreign language specialty, colleges usually sacrifice some needs of the foreign language specialty to maximally meet the need of science and engineering disciplines. Colleges need to pay attention to the problem of unreasonable resource allocation. Besides, the foreign language specialty should enjoy its rights and have its own space in discipline construction.

\section{Corresponding countermeasures and strategies of the innovative system of foreign language specialty}

The foreign language specialty faces numerous challenges in the transformation and development period of colleges. However, it is the emphasis of the problem to deeply think and research countermeasures for such challenges. The foreign language specialty' s construction of innovative discipline system in the transformation and development period will help the foreign language specialty greatly. Based on the above challenges, how does this innovative system face them? The strategy research can be carried out generally in the following aspects.

\section{To strengthen connotation construction and enhance the quality of talents}

The first point of discipline construction of foreign language specialty is the connotation construction of disciplines. As for a foreign language specialty, it is required to construct its own preponderant discipline without average development. With its own advantages, a college' s disciplinary development can be mobilized and then the disciplinary connotation can be profound.

\section{To increase discipline innovations and place scientific research in its deserved place}

During discipline construction, a foreign language specialty should be inclined to carrying out scientific research and enhancing the intensity of disciplinary innovation. In the new period of transformation and development of colleges, the innovative system of foreign language specialty should emphasize the innovative ideas and integrate innovation into the scientific research of foreign language specialty so that more vigor can be injected to the disciplinary development. 


\section{To enhance the teaching staff construction and improve teachers' comprehensive quality}

Teachers are the leaders of disciplinary development, especially for a foreign language specialty. It is required to strengthen the construction of foreign language teaching staff in colleges synchronously from recruitment to teaching. With respect to teaching, it is required to establish an evaluation and feedback mechanism so as to comprehensively learn a teacher' s comprehensive quality and solve all sorts of targeted problems.

\section{To correct the attitude and reasonably allocate the college resources}

As a specialty of liberal arts, the foreign language specialty should be treated by colleges without discrimination. A college should not be partial to the construction of a certain discipline. Only when resources are allocated reasonably, the innovative development of foreign language specialty can be continued step by step. The foreign language specialty needs to continuously make innovations by reasonably using such resources so as to raise the comprehensive level of the discipline to its deserved height.

\section{Conclusion}

The transformation and development period of colleges is the period for the development of college disciplines with both opportunities and challenges. The foreign language specialty should overcome such challenges, fully grasp opportunities, and apply the innovative system in teaching and scientific research for foreign language specialty based on continuous innovation and reform so as to make more contributions to China' s economic and social development.

\section{Acknowledgement}

Soft science project of Henan Department of Science \& Technology, "Study on Challenges of Foreign Language Specialty and Innovative System in the Transformation and Development Period of Colleges" (Project No.: 142400411072)

\section{References}

[1] Fan Wei. Reflection on liberal education of applied technology-oriented colleges in the transformation and development period, China Adult Education, 2014, (22): 19-21.

[2] Pu Zhengfang. Vocational development of college English teachers in the transformation and development period of local colleges, Journal of Wenshan University, 2015 (04).

[3] He Yamei. Analysis on cultivation of comprehensive English talents, Heilongjiang Researches on Higher Education, 2004, (4): 108-110.

[4] Fang Jianzhuang. Crisis of foreign language specialty in the 21st century and countermeasures, Higher Education Exploration, 2001, (1): 76-79.

[5] Cheng Xiaotang. Discussion on the way of foreign language specialty in colleges, Shandong Foreign Languages Teaching Journal, 2013 (4): 48-52.

[6] Wen Qiufang. Challenges and countermeasures for practicing the diversified outlook on talents in English specialty, Foreign Language Teaching and Research, 2014 (1): 118-125. 